\title{
The Role of The Social Service In The Street Children's Support In Medan City
}

\author{
Dameria Sihite \\ \{dameriasihite151261@gmail.com\} \\ Postgraduate Program, Pelita Kebenaran School of Theology
}

\begin{abstract}
The Child Protection Law No. 35 of 2014 explains that every child is a potential as the bearer of national ideals into the future, playsa strategic role and has special characteristics and traits that guarantee the continuity of the nation existence in the future. Therefore they need to have the widest opportunity for growth and to be developed optimally, physically, mentally and socially. Protection measures are needed to realize the welfare of children by guaranteeing the fulfillment of rights and the existence of treatment without discrimination.Street children are children who spend part of their time to earn a living or roam the streets or other public places. The Director of Child Welfare, Family and Elderly Affairs, the Department of Social Affairs explained that street children are children who spend most of their time earning a living or roaming the streets or other public places. Their ages range from 6 years to 18 years. Street children referred to here are those under 15 years of age with a personality more mature than their age. Physically and naturally being adults even though they are still children. The presence of street children is often seen as a mirror of urban poverty or the result of failure to adaptto the dynamic life of a big city. The time spent on the road is more than 4 hours a day. Basically street children spend their time on the road.
\end{abstract}

Keyword : Children, Social Service

\section{Introduction}

The role of social services is very much needed in the empowerment of street children so that with the role of the office social service the number of street children can be reduced. Therefore, the Social Service who are in the area of social welfare provides motivation or services to existing street children. This is realized through community social programs, one of the programs for empowering street children. The nature of street children is as people who need attention from others, especially from the government. Examples include providing education or training for street children. Although various efforts have been carried out by the social service, the reality is that many obstacles are found,such as the parents of street children still motivating their children to become beggars.

The social service of an institution in the city of Medan has a role to empower street children in the city of Medan. In this case, to achieve the vision and mission of the Medan city social service, especially about street children and others, this institution monitors the area of Medan in assigning the community order unit (Satpol PP) to perform raids on roaming children on the streets. Child Protection Law No. 35 of 2014 explains that every child as potential and the bearer of national ideals has a strategic role and has special characteristics 
and traits that guarantee the continuity of the nation and state's existence in the future. Therefore they need to have the widest opportunity for growth and to develop optimally physically, mentally and socially. Therefore protection measures are needed to realize the welfare of children by providing guarantees for the fulfillment of rights and the existence of treatment without discrimination.

Street children are children who spend part of their time to earn a living or roam the streets or other public places. The Director of Child Welfare, Family and Elderly Affairs, the Department of Social Affairs explained that street children are children who spend most of their time earning a living or roaming the streets or other public places. Their ages range from 6 years to 18 years. Street children referred to here are those under 15 years of age with a personality more mature than their age. Physically and naturally being adults even though they are still children.The presence of street children is often seen as a mirror of urban poverty or the result of failure to adaptto the dynamic life of a big city. The time spent on the road is more than 4 hours a day. Basically street children spend their time on the road.

The Directorate of Child Welfare, Family and Elderly Ministry of Social Affairs explained that street children are children who spend most of their time in earning a living or roaming the streets or other public places. Their ages range from 6 years to 18 years. In addition, as explained by the Ministry of Social Affairs, indicators of street children according to their age are children aged between 6 and 18 years. From this explanation, it can be concluded that those who can be categorized as street children have ages ranging from 6 to 18 years.

According to Surbakti et al, based on the results of studies in the field, broadly speaking street children are divided into 3 groups, namely: First, Children on the street, namely children who have economic activities - as child workers on the road, but still have relationships strong with their parents. Part of their income in this category is to help strengthen their family's economic support because the burden or pressure of poverty that must be borne by their parents cannot be solved alone. Secondly, street children are children who participate fully.

The first trend can be referred to as the primary tendency of the meaning of empowerment. While the second or secondary tendency emphasizes the process of stimulating, encouraging or motivating individuals to have the ability or empowerment to determine what is their life choice through a dialogue process.

The choice of method/technique will determine the success of the process and results of the empowerment activities. The methods used are as follows:

1. Building an assistive relationship that is realized in the form of reflecting, responding to empathy for the target, respecting the party and the rights of the client/target to determine his own destiny, respecting the differences and uniqueness of the individual, and emphasizing the client's cooperation

2. The approach by sending messages through socialization and extension education, especially for street children about the importance of changing negative and positive behaviors based on their own awareness so that people can receive them back in the midst of society

3. Method of delivery through discussion focused on groups, by focusing on groups and involving the heads of street childrengroups, members of street children, agents of change

To create an atmosphere or climate that allows existing potential to be developed. Here the starting point is the introduction that every human being has the potential to be developed. Another problem is how to strengthen the potential or power possessed by the community. This strengthening involves concrete steps to provide various inputs and open access to 
various opportunities to become empowered. This means that community empowerment in this case street children is how to provide motivation and opportunity to every member of street children to be able to carry out productive activities in accordance with their potential and can be accounted for.

In the context of empowerment, the role of the government through the Office of Social Affairs needs to be encouraged to achieve the learning objectives of being independent, so that street children can tread a brighter and more advanced future. There are various efforts in the empowerment of street children. Efforts to empower street children can be shaped through programs such as:

1. Street Based

The approach is carried out to safeguard and assist street children to recognize, maintain relationships and communication as well as handlingcases on the road such as counseling, discussion, literacy games and providing information. Street Based Orientation is directed at efforts to ward off influence. Due to negative influence of the street, equipping street children with positive values and insights, such as the Children's FriendCar program, is extremely necessary.

2. Center based

This is an approach that positions street children as recipients of services in a center or activity center and place of residence in particular period of time. During their time at the center they will get service until they reach the desired destination. Like a boarding house or a home.

3. Family and Community based

This is an approach that involves families and communities that aim to prevent children from going down the streets and encourages the provision of facilities to fulfill children's needs. Family and Community based leads to efforts to raise awareness and responsibility and participants of family members and communities in overcoming the problems of street children.

\section{Empowerment Strategy}

Empowerment strategies are activities that have clear objectives and must be achieved. Therefore each implementation needs to be based on strategies for success to form potential children in the future.Pranarkaand Vidhyandika (1996) explain that empowerment process contains two trends: first, the empowerment process that emphasizes giving and transferringstrength, power or ability to the community so that individuals possess power.The concept of empowerment is the same as entrusting authority that comes from the word "power". Therefore, before empowering others, one should be able to empower themselves first. At least every empowered individual has certain characteristics. Empowerment is usually given to strengthen structure

\section{Street Children Concept}

Street children or homeless children or sometimes euphemistically called independent children. RanoKarno's proposal while serving as UNICEF Ambassador, described them as marginalized children who are dependent on the treatment of affection because most of them 
at a relatively early age had to deal with a harsh and even very hostile city environment. In various corners of the city it often happens that street children must survive in ways that are socially insufficient or even unacceptable to the general publicto avoid hunger and compulsion to help their families. Not infrequently they are also labeled as a disturbance of order and trash to the city dirty, so raids is not something surprising to them.

Marginal, vulnerable, exploited are unfortunately very appropriate terms to describe the condition and life of street children. They are marginal because they wear a type of clothing that does not reflect a future in their career. They are undervalued and generally do not promise any prospects in the future. They are vulnerable because of the risks that must be borne due to very long hours of work really in terms of health and social are very vulnerable. They are exploited because they often have a bargaining position (bargaining position) which is very weak, subordinated, and treated to be an object.

\begin{tabular}{cc}
\hline Year & Number Of Street Children \\
\hline 2017 & 54 children \\
2018 & 68 children \\
\hline
\end{tabular}

\section{Photos Of Street Children}

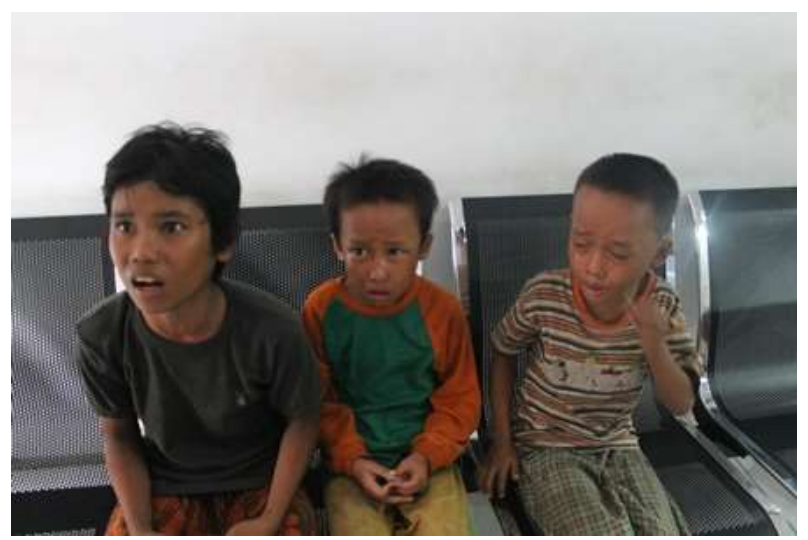




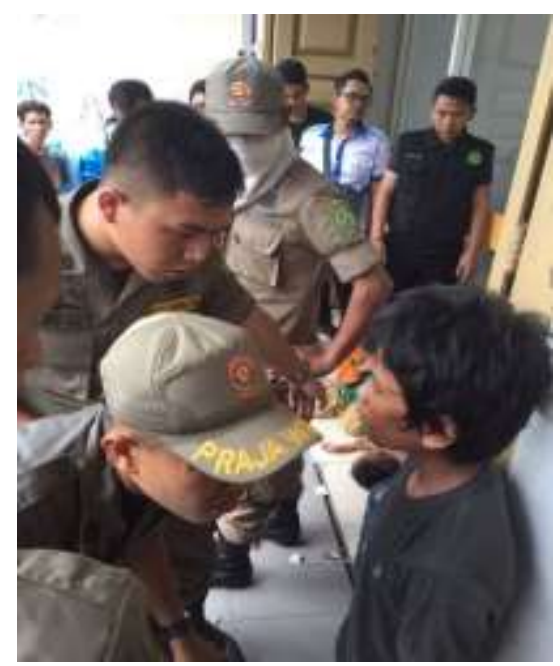

